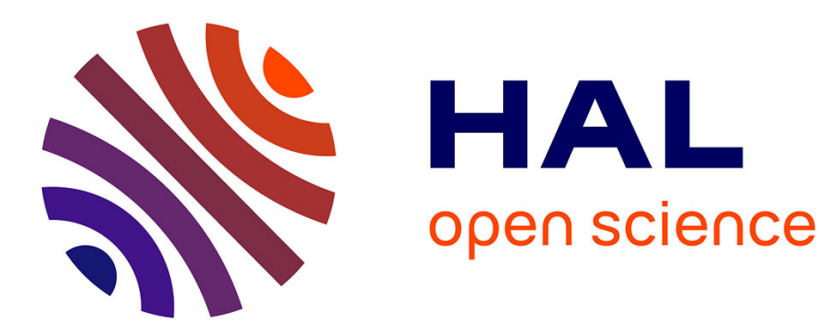

\title{
Toughening mechanisms in interfacially modified HDPE/thermoplastic starch blends
}

Aurélie Taguet, Martin N. Bureau, Michel A. Huneault, Basil D. Favis

\section{To cite this version:}

Aurélie Taguet, Martin N. Bureau, Michel A. Huneault, Basil D. Favis. Toughening mechanisms in interfacially modified HDPE/thermoplastic starch blends. Carbohydrate Polymers, 2014, 114, pp.222229. 10.1016/j.carbpol.2014.07.073 . hal-02914341

\section{HAL Id: hal-02914341 \\ https://hal.science/hal-02914341}

Submitted on 7 Jan 2021

HAL is a multi-disciplinary open access archive for the deposit and dissemination of scientific research documents, whether they are published or not. The documents may come from teaching and research institutions in France or abroad, or from public or private research centers.
L'archive ouverte pluridisciplinaire HAL, est destinée au dépôt et à la diffusion de documents scientifiques de niveau recherche, publiés ou non, émanant des établissements d'enseignement et de recherche français ou étrangers, des laboratoires publics ou privés. 


\title{
Toughening mechanisms in interfacially modified HDPE/thermoplastic starch blends
}

\author{
Aurélie Taguet $^{\mathrm{a}, \mathrm{c}, *}$, Martin N. Bureau $^{\mathrm{b}, 1}$, Michel A. Huneault $^{\mathrm{b}, 2}$, Basil D. Favis $^{\mathrm{c}}$ \\ a Centre des Matériaux des Mines d'Alès (C2MA), Ecole des Mines d'Alès (Institut Mines Télécom), 6 avenue de Clavières, F-30319 Alès Cedex, France \\ ${ }^{\mathrm{b}}$ Industrial Materials Institute, National Research Council Canada, 75 Bd de Mortagne, Boucherville, QC, Canada J4B 6Y4 \\ c CREPEC, Department of Chemical Engineering, Ecole Polytechnique de Montréal, 2900 Bd Edouard Montpetit, PO 6079, Station Centre-Ville, Montréal, QC, \\ Canada $\mathrm{H} 3 \mathrm{C} 3 \mathrm{A7}$
}

\begin{abstract}
A B S T R A C T
The mechanical behavior of polymer blends containing $80 \mathrm{wt} \%$ of HDPE and $20 \mathrm{wt} \%$ of TPS and compatibilized with HDPE-g-MA grafted copolymer was investigated. Unmodified HDPE/TPS blends exhibit high fracture resistance, however, the interfacial modification of those blends by addition of HDPE-g-MA leads to a dramatic drop in fracture resistance. The compatibilization of HDPE/TPS blends increases the surface area of TPS particles by decreasing their size. It was postulated that the addition of HDPE-g-MA induces a reaction between maleic anhydride and hydroxyl groups of the glycerol leading to a decrease of the glycerol content in the TPS phase. This phenomenon increases the stiffness of the modified TPS particles and stiffer TPS particles leading to an important reduction in toughness and plastic deformation, as measured by the EWF method. It is shown that the main toughening mechanism in HDPE/TPS blends is shear-yielding. This article demonstrates that stiff, low diameter TPS particles reduce shear band formation and consequently decrease the resistance to crack propagation.
\end{abstract}

Keywords:

Starch

Glycerol

Toughness

Blends

Compatibilization

\section{Introduction}

Starch is a low cost, hydrophilic and biodegradable renewable resource with limited mechanical performance. Its ductility can be improved by the addition of a plasticizer such as glycerol to water-swollen starch granules in the presence of heat and high shear (Averous, 2004; Otey, Westhoff, \& Russell, 1977; Swanson, Shogren, Fanta, \& Imam, 1993). The resulting plasticized starch is known as thermoplastic starch (TPS). To decrease its hydrophilicity and improve its mechanical properties, TPS can be melt-blended with polyolefins, such as polyethylene (PE) (Bikiaris \& Panayiotou, 1998; Bikiaris et al., 1998; Rodriguez-Gonzalez, Ramsay, \& Favis, 2003; St-Pierre, Favis, Ramsay, Ramsay, \& Verhoogt, 1997; Wang, Yu, \& Yu, 2005). PE and TPS form immiscible blends with a high interfacial tension. Their interfacial interactions can be improved

\footnotetext{
* Corresponding author at: Centre des Matériaux des Mines d'Alès (C2MA), Ecole des Mines d'Alès (Institut Mines Télécom), 6 avenue de Clavières, F-30319 Alès Cedex, France. Tel.: +3346678 56 87; fax: +3346678 5365 .

E-mail address: aurelie.taguet@mines-ales.fr (A. Taguet).

1 Present address: Sanexen Environmental Services Inc., 9935, Catania Avenue, Entrance 1, Brossard, QC, Canada J4Z 3V4.

2 Present address: Chemical \& Biotechnological Engineering, Université de Sherbrooke, Sherbrooke, QC, Canada J1K 2R1.
}

by blending with copolymer interfacial modifiers (Cerclé, Sarazin, \& Favis, 2013; Prachayawarakorn, Sangnitidej, \& Boonpasith, 2010; Yin, Dong, Wang, \& Yin, 2008), the most common of which is PE grafted with maleic anhydride, PE-g-MA (Bikiaris \& Panayiotou, 1998; Bikiaris et al., 1998; Sailaja \& Chanda, 2000; Wang, Liu, \& Sun, 2004). In a previous article on HDPE/TPS blends (Taguet, Huneault, \& Favis, 2009), it was shown that the glycerol-rich domains of TPS dispersed phase migrated to the interface, and played a lubricant role, which resulted in very high mechanical properties. Moreover, upon interfacial modification of HDPE/TPS with HDPE-g-MA, maleic anhydride can react with glycerol, decreasing the glycerol content of the TPS particle and lead to micelle formation in the matrix. It was shown that a higher glycerol content leads to a higher amount of copolymer necessary to saturate the interface. It was also demonstrated that high tensile properties were obtained for modified HDPE/TPS blends due to a double mechanism at the interface, related to the formation of glycerol and copolymer layers. Sailaja, Reddy, and Chanda (2001) reported a similar improvement of the mechanical properties of LDPE with varying proportions of plasticized tapioca starch in presence of a compatibilizer (poly(ethylene-co-glycidyl methacrylate)). Micrographs of impact and tensile fractured surfaces showed a brittle-ductile failure transition with increasing amounts of copolymer at TPS contents higher than $30 \mathrm{wt} \%$. Regarding the literature on polyolefin/TPS blends, 
a few articles dealing with the mechanical performances of such blends have been reported (Gupta, Sharma, \& Kumar, 2008; Ning, Jiugao, Xiaofei, \& Ying, 2007; Tena-Salcido, Rodriguez-Gonzalez, Mendez-Hernandez, \& Contreras-Esquivel, 2008) which did not address failure mechanisms. Compatibilized polyolefin/TPS blends have been shown to be complex systems due to the presence of glycerol and its possible reactivity with the compatibilizer.

Fracture toughness measurement is an interesting tool to characterize the state of the interface in a polymer blend (Ahn \& Paul, 2006; Bucknall \& Paul, 2009; Laura, Keskkula, Barlow, \& Paul, 2003; Laurens, Creton, \& Léger, 2004). The main toughening mechanisms in polymer blends are identified to be cavitation, crazing and/or shear-yielding (Mai, Wong, \& Chen, 1999; Wu, Chan, \& Mai, 1999; Yee \& Pearson, 1986). While crazing is the main toughening mechanism of glassy polymers (Brown, 1991), cavitation or void growth is mostly observed in rubber toughened polymers (Bagheri \& Pearson, 1996; Bucknall, Karpodinis, \& Zhang, 1994). Shearyielding is the process by which most ductile polymers extend to high strains in standard tests. Chain segments slip past each other in response to shear stresses, resulting in localized deformations in the yield zone while remaining close to constant volume (Bowden \& Raha, 1970; Brady \& Yeh, 1971, 1973). Other phenomena such as crack bifurcation and/or deflection by rubber particles (Kaber \& Evans, 1983; Pearson \& Yee, 1991), rubber-particle stretching and bridging (Kunz-Douglass, Beaumont, \& Ashby, 1980; Pearson \& Yee, 1991) and formation of a plastic zone ahead of the crack (Bascom \& Cottington, 1976; Bascom, Cottington, Jones, \& Peyser, 1975; Bascom, Cottington, \& Timmons, 1977; Bascom \& Hunston, 1978) contribute to the toughening mechanism of polymer blends. In most polymer blends, these different toughening mechanisms occur simultaneously (Brady \& Yeh, 1973; Bucknall et al., 1994).

A tensile dilatometry test can be performed by measuring the volume strain as a means of identification of the deformation mechanism(s) taking place during the course of a usual stress-strain experiment (Bucknall \& Clayton, 1971). Indeed, it is possible to differentiate deformation mechanisms that induce volume changes, such as crazing and cavitation, or not, such as shear-yielding. Bucknall and Clayton (1971) were the first to introduce the tensile dilatometry approach to evaluate quantitatively the deformational mechanisms of rubber-toughened polystyrene. The rate of volume change was related directly to the rate of crazing. Indeed, during a tensile or a creep test, the slope of the volume strain, $\Delta V / V_{0}$ against longitudinal (also called axial) strain, $\varepsilon_{a}$, curve equals zero for a pure shear-flow process, and equals unity for a pure crazing or cavitation process. The tensile dilatometry tests were performed to study the contribution of cavitation and crazing to the fracture resistance in many rubber-toughened plastics, such as elastomermodified epoxies (Yee \& Pearson, 1986), PMMA and PP (Naqui \& Robinson, 1993), rubber-modified nylon (Borggreve, Gaymans, \& Eichenwald, 1989), HDPE/nylon 6 (Fellahi, Favis, \& Fisa, 1995). The characterization of the toughness of some polymer blends has been well-studied (Mai, Wong, \& Chen, 1999; Williams, 1984; Wong, Mai, \& Chen, 2003). In the case of ductile fracture the well-known linear elastic fracture mechanics (LEFM) concept cannot be applied, because considerable energy is dissipated in the material creating extensive plasticity ahead of the crack tip. Kim and Mai (1991), Mai et al. (1999), Mai and Cotterell (1985, 1986), Mai, Cotterell, Horlyck, and Vigna (1987), Wu and Mai (1996) have developed a methodology based on Broberg's $(1971,1975)$ theory of fracture to characterize the fracture behavior of polymeric materials. According to this essential work of fracture (EWF), and under a plane-stress state, the total work of fracture generated during crack growth, $W_{f}$, can be divided into two components: (i) the essential work of fracture $\left(W_{e}\right)$, associated to the work spent in the inner fracture process zone where $W_{e}$ is a property of the material and, (ii) the non-essential work of fracture $\left(W_{p}\right)$, dissipated in the outer plastic zone. $W_{p}$ is geometry dependent. The EWF method is a useful technique to measure the toughness in ductile materials as it separates the work dissipated in the plastic deformation zone from the work spent to create new surfaces under plane stress conditions. Most other methods require plane strain conditions. In 2010, an extensive review dealing with the application of the EWF concept was published (Barany, Czigany, \& Karger-Kocsis, 2010), listing all the articles on EWF applied to polymers, blends and composites. Chaléat, Halley, and Truss (2008) evaluated the influence of the moisture content on the tensile properties of plasticized starch/high molecular weight polyol blends by using EWF. As the moisture content increases, the material becomes more ductile and EWF measurements highlight a strong dependence of the fracture behavior on the moisture content of this material.

In the present article, the evaluation of the toughness of HDPE/TPS and especially the identification of the mechanisms responsible for fracture resistance are addressed by investigating the resistance to crack initiation and/or propagation of the biobased TPS phase.

\section{Experimental}

\subsection{Materials}

The high density polyethylene (HDPE), supplied by Nova Chemicals (Calgary, Canada), was a Sclair ${ }^{\circledR}$ HDPE2710 (MFI=17). The native wheat starch (Supergell 1203-C) and the glycerol were obtained from ADM (Candiac, Canada) and Laboratoire MAT (Beauport, Canada), respectively. The wheat starch was composed of $25 \mathrm{wt} \%$ of amylose and $75 \mathrm{wt} \%$ of amylopectin. The glycerol was pure at $99.5 \mathrm{wt} \%$ and contained $0.5 \mathrm{wt} \%$ water. The HDPE copolymer grafted with maleic anhydride (HDPE-g-MA) was purchased from Dupont (Fusabond ${ }^{\circledR}$ E MB-265D with a MFI $=12$ ). The wt\% MA content was calculated on a weight basis via elemental analysis and was equal to $3.9 \%$.

\subsection{Blend preparation}

Starch granules were gelatinized, plasticized with glycerol and water and blended with HDPE and compatibilizer in a one-step extrusion process. Blends were prepared containing $20 \mathrm{wt} \%$ of TPS and $80 \mathrm{wt} \%$ of HDPE. The compatibilizer was added with the HDPE, at various rates. All compatibilizer concentrations are based on the TPS content.

The processing of the polyethylene/thermoplastic starch blends was based on a process developed previously (Favis, RodriguezGonzalez, \& Ramsay, 2005; Favis, Rodriguez, \& Ramsay, 2003; Rodriguez-Gonzalez et al., 2003). The extrusion system was composed of a single-screw extruder (SSE) connected midway to a co-rotating twin-screw extruder (TSE). A starch/glycerol/water suspension (detailed information for this starch suspensions are given elsewhere (Taguet et al., 2009)) was fed in the first zone of the TSE. Native starch was gelatinized and plasticized and volatiles were extracted in the first part of the TSE. Molten HDPE and copoly$\operatorname{mer}\left(T=160^{\circ} \mathrm{C}\right)$ were fed from the SSE to midway on the TSE. TPS, HDPE and copolymer were then mixed in the latter part of the TSE. The TSE screw speed was 150 rpm for all blends. A three-hole strand die (diameter $3 \mathrm{~mm}$ ) was used and strands were water cooled, followed by air cooling and then pelletized. After plasticization of the starch, most of the water was removed during venting. Hence, the final TPS can be considered as a binary blend containing starch and glycerol. Under such conditions, the final glycerol contents of the TPS after extrusion were $24 \mathrm{wt} \%, 28 \mathrm{wt} \%, 36 \mathrm{wt} \%$ and $40 \mathrm{wt} \%$, and are referred to as TPS24, TPS28, TPS36 and TPS40, respectively. The final blends are identified by the following nomenclature: 
for example, 20TPS36C9 stands for a blend containing $20 \mathrm{wt} \%$ of TPS36 and $9 \mathrm{wt} \%$ of HDPE-g-MA (based on TPS); indicating that this blend contains $78.2 \mathrm{wt} \%$ of HDPE, $20 \mathrm{wt} \%$ of TPS36 and $1.8 \mathrm{wt} \%$ of HDPE-g-MA.

\subsection{Tensile properties and fracture mechanisms}

After extrusion, samples were injection-molded into dogbone specimens of $57.00 \mathrm{~mm}$ in gage length, $9.70 \mathrm{~mm}$ in width and $3.05 \mathrm{~mm}$ in thickness. Tensile properties were investigated and the profile of the elongated specimen was studied to investigate the fracture mechanism using tensile dilatometry. Tensile tests were performed according to ASTM D638 with an Instron 4400R universal testing machine at a crosshead speed of $50 \mathrm{~mm} / \mathrm{min}$. Elastic modulus, elongation at break and strain at yield were measured from the obtained stress-strain curves. The test was performed at a crosshead speed of $5 \mathrm{~mm} / \mathrm{min}$ and stopped just prior to necking and samples were cryofractured.

\subsection{Scanning electron microscopy and image analysis}

The cryofractured surfaces were observed under a Jeol SM 840 scanning electron microscope (SEM) operating at a voltage of $5 \mathrm{kV}$. Specimens were primarily coated with a thin layer of gold-platinum by physical vapor deposition. The method employed for particle size measurements is given elsewhere (Taguet et al., 2009).

\subsection{Tensile dilatometry}

Volume change measurements were carried out from dogbone specimens using an Instron universal mechanical tester 55R1123 equipped with a video-extensometer (Norwood, MA). A constant strain rate of $50 \mathrm{~mm} / \mathrm{min}$ was used. Axial and transverse extensions were measured with a video extensometer. It is assumed, according to Poisson's ratio, that the deformation in the thickness is equal to that in the width. The volume strain $\Delta V / V_{0}$ is calculated using the formula:

$\frac{\Delta V}{V_{0}}=\left(1+\varepsilon_{a}\right)\left(1+\varepsilon_{T}\right)^{2}-1$

where $\Delta V$ and $V_{0}$ are the change in volume and the original volume, respectively, and $\varepsilon_{a}$ and $\varepsilon_{T}$ represent the axial and the transverse strain, respectively. Note that $\varepsilon_{T}$ assumes a negative value.

$\frac{\mathrm{d}\left(\Delta V / V_{0}\right)}{\mathrm{d} \varepsilon_{a}}=\left(1+\varepsilon_{T}\right)^{2}$

Hence, at the yield point $a, \mathrm{~d}\left(\Delta V / V_{0}\right) / \mathrm{d} \varepsilon_{a}=0$ indicates that shear deformation is the only non-Hookean deformation mechanism. On the contrary, at the yield point $a, \mathrm{~d}\left(\Delta V / V_{0}\right) / \mathrm{d} \varepsilon_{a}=1$ indicates that cavitation and/or crazing are the only mechanisms responsible for volume changes. $\Delta V / V_{0}$ was thus plotted $v s . \varepsilon_{a}$ for HDPE, unmodified and interfacially-modified 20TPS24, 20 TPS28 and 20TPS36 blends. For each blend the wt\% of copolymer corresponds to the critical concentration $\left(C_{\text {crit }}\right)$ in emulsification curves. In all experiments the sample formed a neck and further interpretation of the $\Delta V / V_{0} v s$. axial strain curve is no longer possible due to the non-homogeneous deformation along the specimen gage length.

\subsection{Notched Izod impact tests}

After extrusion, samples were injection molded with a Sumitomo SE50S injection machine under rectangular bars. The dimension of the specimens was $62.10 \times 12.40 \times 4.62 \mathrm{~mm}^{3}$. The notched samples were cut in the middle of the length. Samples were conditioned for $48 \mathrm{~h}$ at $23^{\circ} \mathrm{C}$ under $50 \%$ of humidity. Then, notched specimen measurements were performed with a Resil 25 Izod impact tester from Ceast and according to ASTM D256 and ASTM 4812, respectively. Seven specimens were tested and their average value was reported.

\subsection{Essential work of fracture}

Fracture tests were performed by the EWF method using double edge-notched specimens of $80.45 \mathrm{~mm}$ in length, $30.60 \mathrm{~mm}$ in width and $3.20 \mathrm{~mm}$ in thickness. Specimens were tested with a $500 \mathrm{kN}$ load cell, at a cross-head rate of $5 \mathrm{~mm} / \mathrm{min}$. At least fifteen specimens were tested in a ligament length ranging from 5 to $23 \mathrm{~mm}$.

Under plane-stress conditions, the total work of fracture $\left(W_{f}\right)$ is divided into an essential part $\left(W_{e}\right)$ and a non-essential one $\left(W_{p}\right)$, corresponding to the inner or fracture process zone and to the outer plastic deformation zone, respectively. Hence, $W_{e}$ represents all energy absorbed to create new surfaces, whereas $W_{p}$ gathers all energy dissipated outside of the fracture surface.

$W_{f}=W_{e}+W_{p}$

where $W_{e}$ is a function of the area $1 \times t\left(W_{e}=w_{e} \times 1 \times t\right), W_{p}$ is proportional to $l^{2} \times t\left(W_{p}=w_{p} \times l^{2} \times t\right)$, where $l$ and $t$ are the ligament length and thickness, respectively.

$W_{f}=W_{e}+1 \times \beta w_{P}$

where $\beta$ is a shape factor related to the geometry of the plastic zone (Mai et al., 1999; Test Protocol for Essential Work of Fracture (Version 6)). Finally, $w_{f}$ is determined by calculating the integral under the load-displacement curve for every ligament length $(l$ in $\mathrm{mm})$. Therefore, $w_{e}$ and $\beta w_{p}$ are obtained by least-squares regression of $w_{f} v s . l ; w_{e}$ being the $y$-axis intercept and $\beta w_{p}$, the slope of the line. EWF testing was only performed on plasticized 20TPS28 and 20TPS36 blends.

\section{Results}

The results of the particle size analysis and mechanical testing of interfacially-modified and unmodified blends containing TPS24, TPS28, TPS36 and TPS40 are presented in Table 1. Both interfaciallymodified and unmodified blends show a decrease in dispersed phase size when glycerol content is increased, pointing out the importance of the plasticization level. It was shown elsewhere (Taguet et al., 2009) that $24 \%$ of glycerol in starch is not enough to effectively plasticize starch; to be efficient as a plasticizer, glycerol must be added with at least $28 \%$ in starch. Table 1 shows that the elastic modulus is increased when stiff TPS24 particles are added into a HDPE matrix, whereas the addition of TPS particles with higher starch content (TPS28, TPS36 and TPS40) leads to a leveling off or a drop of elastic modulus. A glycerol content of 28 and $36 \mathrm{wt} \%$ led to the highest elongation at break. The addition of a compatibilizer tends to increase the stress at yield $\left(\sigma_{\max }\right)$ due to the improved interfacial adhesion between PE and TPS.

In light of these results, the tensile dilatometry tests were performed on HDPE, 20TPS24 and 20TPS28 and 20 TPS36 blends in order to study their toughening mechanisms. A previous article (Taguet et al., 2009) studied the emulsification curves of all TPS blends as a function of the wt\% of glycerol and reported the critical concentration $\left(C_{\text {crit }}\right)$ that represents the amount of copolymer needed to saturate the interface. This value of $C_{\text {crit }}$ depends on the $\mathrm{wt} \%$ of glycerol and is given in Table 1. For more clarity, the stress and volume change vs. axial strain curves are only presented for unmodified and interfacially-modified 20TPS36 blends in Figs. 1 and 2, respectively. Table 2 summarizes the slope of the volume change vs. axial strain at the yield point obtained for 
Table 1

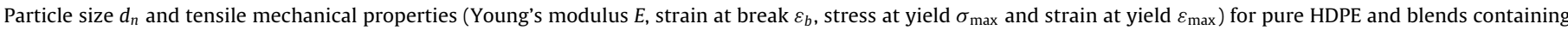
80\% HDPE and 20\% TPS (TPS24, TPS28, TPS36 and TPS40). Blends are unmodified or interfacially-modified with HDPE-g-MA.

\begin{tabular}{|c|c|c|c|c|c|c|}
\hline & wt\% HDPE-g-MA & $d_{n}(\mu \mathrm{m})$ & $E(\mathrm{MPa})$ & $\varepsilon_{b}(\%)$ & $\sigma_{\max }(\mathrm{MPa})$ & $\varepsilon_{\max }(\%)$ \\
\hline HDPE & 0 & - & 1250 & $>900$ & 19.5 & 11.4 \\
\hline 20TPS24 & 0 & 7.85 & $1510( \pm 190)$ & $46( \pm 20)$ & 16.7 & 8.5 \\
\hline 20TPS24C6 & 6 & 1.17 & $1470( \pm 230)$ & $18( \pm 10)$ & 21.2 & 6.9 \\
\hline 20TPS28 & 0 & 4.38 & $1250( \pm 100)$ & $160( \pm 20)$ & 18.0 & 9.3 \\
\hline 20TPS28C9 & 9 & 0.88 & $1100( \pm 120)$ & $310( \pm 100)$ & 19.0 & 8.9 \\
\hline 20TPS36 & 0 & 3.03 & $1180( \pm 160)$ & $200( \pm 35)$ & 17.1 & 9.8 \\
\hline 20TPS36C9 & 9 & 0.55 & $1040( \pm 90)$ & $310( \pm 70)$ & 17.6 & 9.5 \\
\hline 20TPS40 & 0 & 1.13 & $950( \pm 120)$ & $120( \pm 18)$ & 16.7 & 9.8 \\
\hline 20TPS40C13 & 13 & 0.37 & $1110( \pm 200)$ & $210( \pm 60)$ & 17.4 & 10.5 \\
\hline
\end{tabular}

N.B.: standard deviations were added when they are higher then $5 \%$.

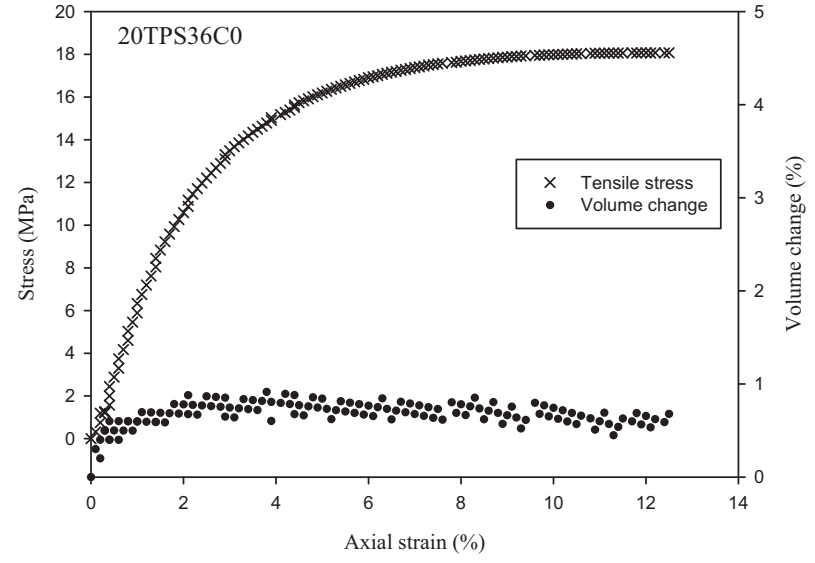

Fig. 1. Stress-axial strain-volume change curves of 20TPS36C0.

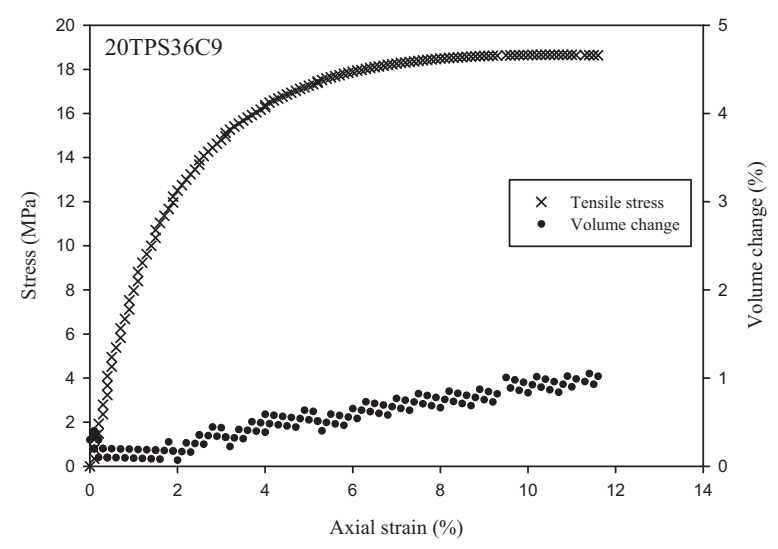

Fig. 2. Stress-axial strain-volume change curves of 20TPS36C9.

pure HDPE and interfacially-modified and unmodified 20TPS24, 20 TPS2 8 and 20TPS36 blends. The yield point is defined as the first maximum on the stress-strain curve, and depends on the material. Figs. 1 and 2 (obtained for 20TPS36C0 and 20TPS36C9, respectively)

Table 2

Slope of the curves plotting $\Delta V / V_{0}$ vs. $\varepsilon_{a}$ at the yield point $\left(\varepsilon_{\max }\right)$ for HDPE and 20TPS24C0, 20TPS24C6, 20TPS28C0, 20TPS28C9, 20TPS36C 0 and 20TPS36C9 blends.

\begin{tabular}{ll}
\hline Blends & Slope of the $\Delta V / V_{0} v s . \varepsilon_{a}$ curve at $\varepsilon_{\max }$ \\
\hline HDPE & 0.08 \\
20TPS24C0 & 0.20 \\
20TPS24C6 & 0.25 \\
20TPS28C0 & 0.02 \\
20TPS28C9 & 0.06 \\
20TPS36C0 & 0 \\
20TPS36C6 & 0.06 \\
\hline
\end{tabular}

exhibit a yield point at $12.2 \%$ and $11.6 \%$ of axial strain, respectively. For both interfacially-modified and unmodified 20TPS36 blends, the volume change is very low. Moreover, Table 2 shows that the slope of $\Delta V / V_{0} v s$. $\varepsilon_{a}$ curves at the yield point is very low for wellplasticized 20TPS28 and 20TPS36 blends, ranging from 0 to 0.06 . However, the slope increases to 0.20 and 0.25 for unmodified and interfacially-modified 20TPS24 blends, respectively. In general, the slope increases from unmodified to modified blends. The very low slopes obtained for 20TPS28 and 20TPS36 blends provide indications that their main toughening mechanism is shear-yielding. The results of tensile dilatometry also show that the interfacial modification with HDPE-g-MA copolymers tends to increase cavitation as a toughening mechanism.

The results of the notched impact tests are presented in Fig. 3. The highest notched impact energy noted for unmodified blends was obtained for a glycerol content of $36 \mathrm{wt} \%$ (it increased from $24 \mathrm{wt} \%$ to $36 \mathrm{wt} \%$ then decreased at $40 \mathrm{wt} \%$ ). Interfacial modification using grafted maleic anhydride led to an overall reduction in the notched impact strength for all blends except for 20TPS40. From these results, it appears that the notched impact strengths of the unmodified blends are governed by the plasticization level of the TPS particles. Low amounts of glycerol ( $24 \mathrm{wt} \%)$ lead to stiff TPS particles and high amount of glycerol ( $40 \mathrm{wt} \%$ ) soften the materials leading to low notched impact strengths. In agreement with results presented elsewhere (Taguet et al., 2009), the results show that a glycerol content of $36 \mathrm{wt} \%$ appears to present a balance between a too low and a too high plasticization level. Upon interfacial modification, the surface area of TPS particles increases as a result of the lower TPS particle size. Since TPS is stiffer and more brittle than PE, even when plasticized, TPS particles act in the soft PE

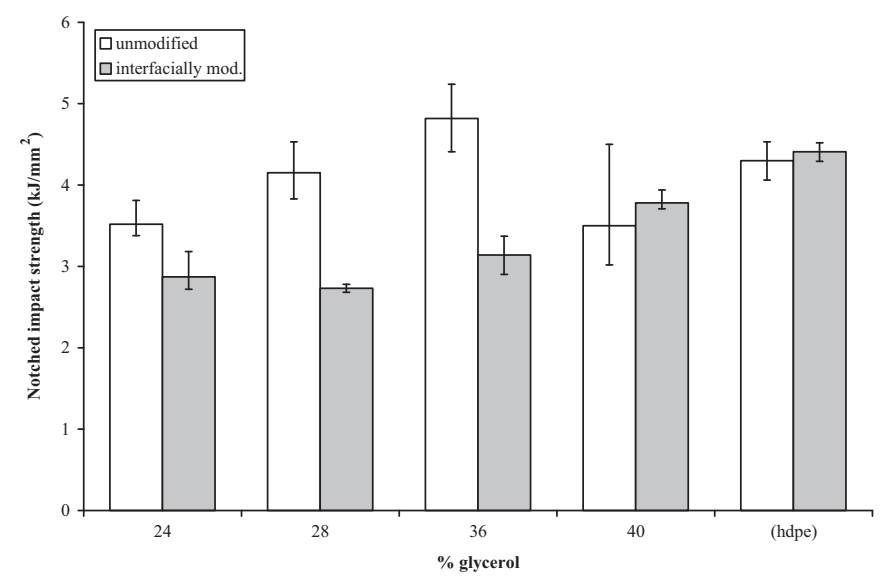

Fig. 3. Notched Izod impact strength (in $\mathrm{kJ} / \mathrm{mm}^{2}$ ) of HDPE and unmodified and interfacially modified blends of compatibilized HDPE matrix (98.2\% HDPE and 1.8\% HDPE-g-MA) and $20 \%$ TPS with various amounts of glycerol ranging from $24 \%$ to $40 \%$. 
Table 3

Values obtained after EWF tests on pure HDPE and blends containing 80\% HDPE, $20 \%$ TPS (TPS28 and TPS36) and HDPE-g-MA copolymer: the essential work $\left(W_{e}\right)$, the non-essential work $\left(\beta W_{p}\right)$ of fracture and the total fracture work for a given ligament length $(l=17.8 \mathrm{~mm})$ are reported.

\begin{tabular}{lclc}
\hline Samples & $W_{e}\left(\mathrm{~kJ} / \mathrm{m}^{2}\right)$ & $\beta W_{p}\left(\mathrm{MJ} / \mathrm{m}^{3}\right)$ & $\begin{array}{l}W_{f}\left(\mathrm{~kJ} / \mathrm{m}^{2}\right) \text { for } \\
l=17.8 \mathrm{~mm}\end{array}$ \\
\hline HDPE & & & 176.0 \\
20TPS28C0 & 36.76 & 7.60 & 49.7 \\
20TPS28C9 & 24.66 & 1.33 & 4.8 \\
20TPS36C0 & 2.76 & 0.12 & 79.0 \\
20TPS36C9 & 19.69 & 3.24 & 12.8 \\
\hline
\end{tabular}

matrix as stress concentration sites. Failure in the notched impact specimens therefore occurs by crack propagation at the TPS-matrix interface. When more such crack propagating particles are present, the notched impact strength is reduced.

The toughness of the plasticized TPS/HDPE blends (i.e. containing TPS28 and TPS36 blends) was evaluated by means of the essential work of fracture (EWF) testing. The fracture properties of HDPE/TPS24 blend was not evaluated because of poor tensile properties. Prior to EWF data treatment, all load at yield vs. ligament length data were analyzed to make sure they were obtained under plane stress conditions. Only those ligament lengths that gave a load at yield data within the $\pm 10 \%$ of the mean load at yield were selected. The load $v s$. extension curves were then examined for self-similarity. The values of $W_{e}$ and $\beta W_{p}$ were then calculated according to Eq. (4) from the linear regression of the specific work of fracture $v s$. ligament length (data are shown in Fig. 4 and Table 3). The total work of fracture $\left(W_{f}\right)$ is dramatically reduced when TPS is added to HDPE, and further reduced when a HDPE-g-MA compatibilizer is added to the blends. For example, the value of $W_{f}$ is reduced by $72 \%$ and 55\% when TPS28 and TPS36 are added to HDPE, respectively. The value of $W_{f}$ is further reduced by $90 \%$ and $84 \%$ when the copolymer is added to 20TPS28 and 20TPS36 blends, respectively. All the non-EWF values decrease upon TPS addition, but follow a different trend with respect to the glycerol content. For example, non-EWF values dropped by, respectively, $83 \%$ and $57 \%$ when $20 \mathrm{wt} \%$ of TPS 28 and TPS36 are added to HDPE. Copolymer addition also led to a very large reduction in non-EWF values $(91 \%$ and $86 \%$ less when copolymer is added to 20TPS28 and 20TPS36, respectively). The EWF and non-EWF results indicate that the introduction of more rigid TPS particles in a ductile HDPE matrix causes the reduction of the total work of fracture, and this reduction is more important for the blend containing lower glycerol content. They also indicate that compatibilization of this blend results in a further very significant reduction of the total work of fracture. When more particles are present in the matrix, as in the case of higher glycerol content or when the copolymer is added, the blends show a lower intrinsic fracture resistance, as indicated by the EWF values. The effect on plastic dissipation (non-EWF) is slightly different; since they act as fracture promoting sites, when a higher number of stiff particles are present in the matrix (e.g. at lower glycerol content (TPS28) or with the copolymer), the process zone extends less, resulting in a lower non-EWF. Indeed, stiff TPS particles reduce localized shear bands formation, effectively reducing overall plastic deformation (Brady \& Yeh, 1973).

Fig. 5 represents micrographs of unmodified and interfacially modified 20TPS24 and 20TPS36 blends after elongation. The micrograph 1 of Fig. 5 clearly identifies void growth around TPS24 particles poorly bonded to the matrix after $55 \%$ of elongation. Moreover the TPS24 droplets are poorly elongated. Micrographs 2 and 4 in Fig. 5 represent compatibilized 20TPS24 and 20TPS36 blends after $30.8 \%$ and $54.2 \%$ elongation, respectively. Those micrographs exhibit no elongation of the TPS particles and void growth can be seen around TPS 24 particles. Finally, the micrograph 3 of Fig. 5, which represents the unmodified 20TPS36 blends after $59.2 \%$ of elongation, clearly identifies the high deformation of the TPS particles in the direction of the applied strain, with no cavitation around the particles. Those four micrographs in Fig. 5 confirm the results obtained in Table 2 (up to the yield point): the tensile deformation of well-plasticized HDPE/TPS blends is governed by a shear-yielding toughening mechanism, with a small increase of cavitation phenomenon after interfacial modification. But, if TPS particles are not sufficiently plasticized (TPS24), cavitation slightly increases.

\section{Discussion}

In the studied blends, $20 \mathrm{wt} \%$ of the HDPE is replaced by a plasticized wheat starch that is a renewable resource of very low cost. It was expected that the addition of an interfacial modifier, such as

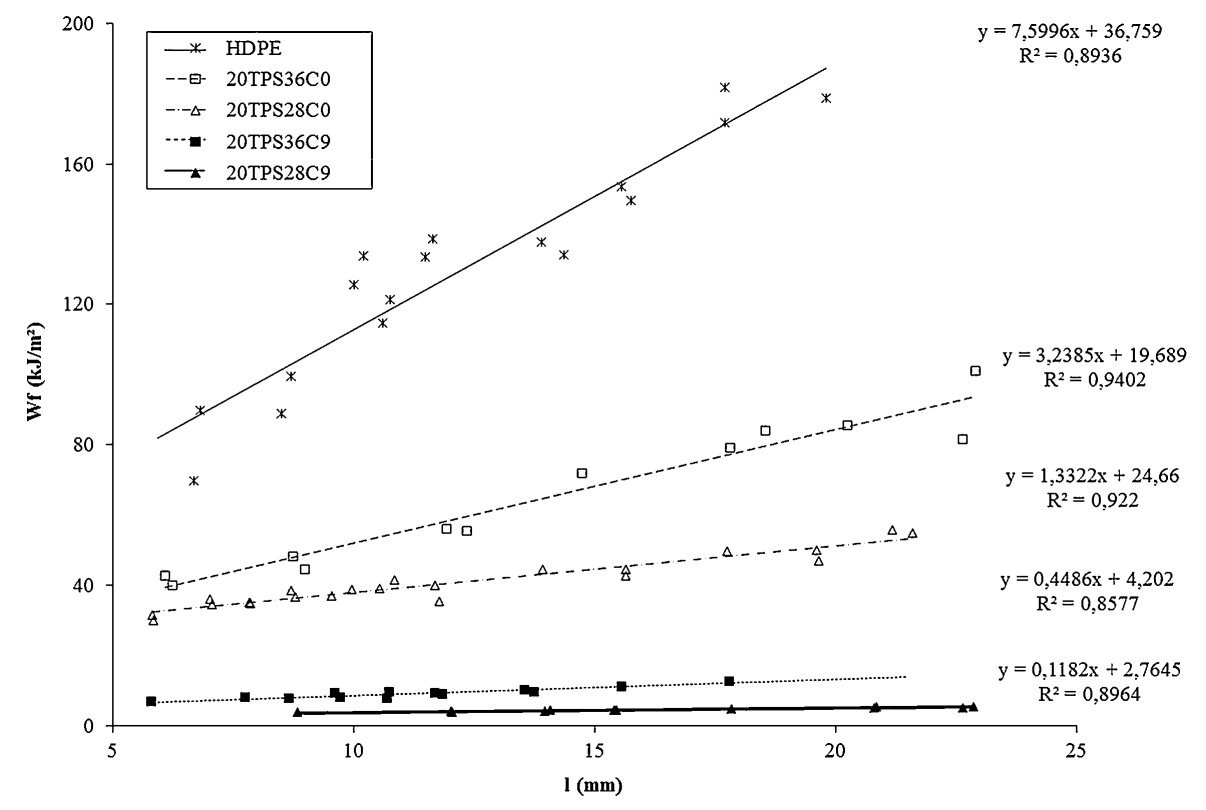

Fig. 4. Specific work of fracture vs. ligament length for HDPE and blends containing $20 \%$ of TPS28 and TPS 36 with $0 \%$ and $9 \%$ of HDPE-g-MA. 

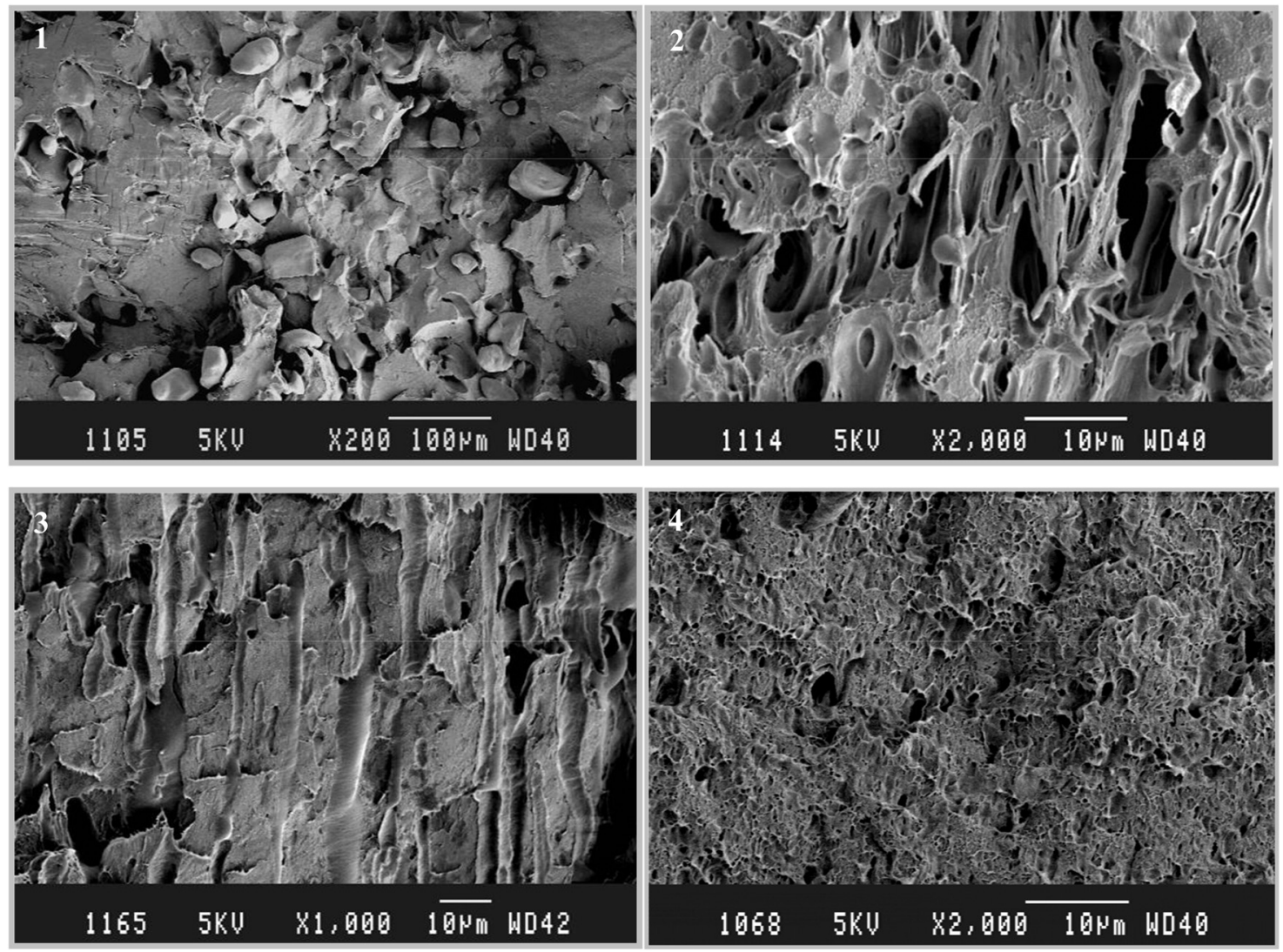

Fig. 5. SEM micrographs of: 20TPS24C0 (1), 20TPS24C6 (2), 20TPS36C0 (3) and 20TPS36C6 (4) blends, elongated at 55, 30.8, 59.2 and $54.2 \%$, respectively, prior to cryofracture.

HDPE-g-MA copolymer would improve the adhesion between both polymer phases and the resulting mechanical properties, especially the fracture behavior (toughness). In reality, the fracture behavior observed, based on EWF and notched Izod impact results, shows that the maleic anhydride compatibilization drastically decreases both toughness and plastic deformation.

The introduction of TPS particles in an HDPE matrix and further compatibilization of the blend leads to important changes in their morphology and their mechanical properties. When the glycerol content is too high ( $40 \mathrm{wt} \%$ ), it leads to an overall softening of the blend (cf. reduction in Young's modulus and the stress at yield in
Table 1). On the contrary, if the plasticization level of the TPS dispersed phase is insufficient (as in the case of 20TPS24 blends), the TPS particles are too stiff and not prone to deformation.

The presence of these stiff particles in a soft matrix leads to a reduction in ductility and impact strengths (Table 1, Fig. 3). This is explained by the volume increase measured by tensile dilatometry (Table 2) indicating voiding, presumably at TPS particles, as observed on fracture surfaces (micrograph 1 in Fig. 5 showing voiding at TPS24 particles). For the well-plasticized blends (20TPS28 and 20TPS36), the addition of a grafted copolymer leads to particle size reduction (as shown in Table 1), but it also decreases
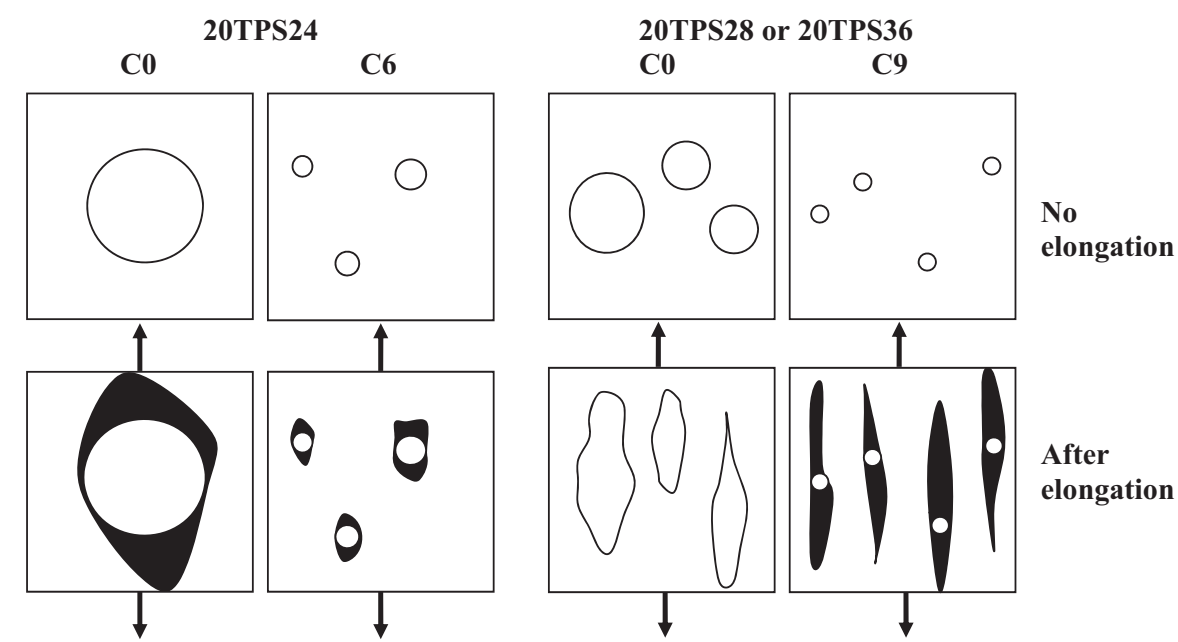

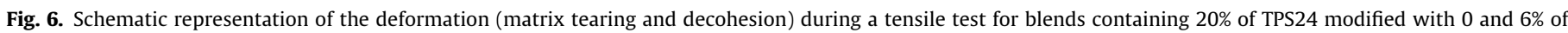
copolymer and for $20 \%$ of TPS 28 or 36 modified with 0 and $9 \%$ of copolymer. Black space around the TPS particles characterizes void growth. 
the glycerol content of the TPS particle, as a result of the reaction between the maleic anhydride groups of the copolymer and the hydroxyl groups of the glycerol, as reported elsewhere (Taguet et al., 2009). This reaction results in a drastic increase of the stiffness of the TPS droplet. Not surprisingly, higher amount of stiff particles in an HDPE matrix reduces the toughness of the blend. Indeed, for all blends, tensile dilatometry tests demonstrate that the main toughening mechanism up to the yield point is shearyielding, but compatibilization is accompanied by voiding at the TPS particles (Table 2 and Micrographs 2 and 4 in Fig. 5). Fig. 6 summarizes the evolution of the microstructure of 20TPS24 and 20TPS28 (or 36) blends during a tensile test. This schematic representation of the modified or unmodified TPS particles after a tensile test indicate void growth around the particles in the case of 20 TPS2 4 blends and compatibilized 20TPS28 or 36 . In this case, TPS particles are stiff and have low deformability, which leads to voiding observed at TPS particles. This result can also explain the impact and EWF measurements. Whereas, for the unmodified 20TPS28 or 36 blends, the flow-induced orientation of the particles and the high deformability of TPS particle shows little cavitation and a dominant shear-yielding mechanism as shown in micrograph 3 in Fig. 5.

Notched impact strengths such as EWF results show the influence of the stiffness and the amount of particles per unit area on the intrinsic fracture resistance. During a fracture test, the crack propagates around the TPS particles. Hence, the higher the amount and the higher the stiffness of the particles, the lower the energy needed to propagate a crack. This explains the toughness decrease when TPS particles are added to HDPE matrix, and when this copolymer is added to the blend. A higher amount of TPS particles leads to the reduction of the process zone extension ahead of the crack tip, which reduces the plastic deformation and consequently the value of the non-EWF.

\section{Conclusions}

HDPE blended with thermoplastic starch can lead to materials with relatively high fracture resistance. The high toughness of HDPE can be maintained by maintaining a low amount of highly deformable TPS particles. That is to say, by adding well-plasticized non-modified TPS particles. Indeed, by decreasing the glycerol content of TPS particles, the addition of HDPE-g-MA dramatically increases the amount of stiff particles. Thus, even if compatibilization increase the adhesion between the phases (Taguet et al., 2009), it decreases the toughness and lead to the reduction of the plastic deformation zone ahead of the crack tip. This contributes to clearly decrease the fracture resistance. Finally, the unmodified blend containing $36 \mathrm{wt} \%$ of glycerol is the one with the highest resistance to fracture.

\section{Acknowledgements}

The authors gratefully acknowledge the financial support received from the Canadian Biomass Innovation Network and the Natural Sciences and Engineering Research Council of Canada through a Strategic Grant. Support from the National Research Council of Canada for experimental testing is also acknowledged.

\section{References}

Ahn, Y.-C., \& Paul, D. R. (2006). Rubber toughening of nylon 6 nanocomposites. Polymer, 47(8), 2830-2838

Averous, L. (2004). Biodegradable multiphase systems based on plasticized starch. Journal of Macromolecular Science Polymer Reviews, C, 44, 231-274.

Bagheri, R., \& Pearson, R. A. (1996). Role of particle cavitation in rubber-toughened epoxies: 1. Microvoid toughening. Polymer, 37, 4529-4538.

Barany, T., Czigany, T., \& Karger-Kocsis, J. (2010). Application of the essential work of fracture (EWF) concept for polymers, related blends and composites: A review. Progress in Polymer Science, 35, 1257-1287.
Bascom, W. D., \& Cottington, R. L. (1976). Effect of temperature on the adhesive fracture behavior of an elastomer-epoxy resin. Journal of Adhesion, 7, 333-346.

Bascom, W. D., Cottington, R. L., Jones, R. L., \& Peyser, P. (1975). Fracture of epoxyand elastomer-modified epoxy polymers in bulk and as adhesives. Journal of Applied Polymer Science, 19, 2545-2562.

Bascom, W. D., Cottington, R. L., \& Timmons, C. O. (1977). Fracture reliability of structural adhesives. Applied Polymer Symposia, 32, 165-188.

Bascom, W. D., \& Hunston, D. L. (1978). Adhesive fracture behavior of CTBN-modified epoxy polymers. In Toughening Plast., Int. Conf. [Prepr.]: Paper No. 22 (p. pp. 27).

Bikiaris, D., \& Panayiotou, C. (1998). LDPE/starch blends compatibilized with PE-g-MA copolymers. Journal of Applied Polymer Science, 70 $1503-1521$

Bikiaris, D., Prinos, J., Koutsopoulos, K., Vouroutzis, N., Pavlidou, E., Frangis, N., \& Panayiotou, C. (1998). LDPE/plasticized starch blends containing PE-g-MA copolymer as compatibilizer. Polymer Degradation and Stability, 59, 287-291.

Borggreve, R. J. M., Gaymans, R. J., \& Eichenwald, H. M. (1989). Impact behavior of nylon-rubber blends 6 . Influence of structure on voiding processes: Toughening mechanism. Polymer, 30, 78-83.

Bowden, P. B., \& Raha, S. (1970). Formation of microshear band in polystyrene and poly(methylmethacrylate). Philosophical Magazine, 22, 463-482.

Brady, T. E., \& Yeh, G. S. Y. (1971). Yielding behavior of glassy amorphous polymers Journal of Applied Physics, 42, 4622-4630.

Brady, T. E., \& Yeh, G. S. Y. (1973). Similarity between craze morphology and shear-band morphology in polystyrene. Journal of Materials Science, 8 1083-1094.

Broberg, K. B. (1971). Crack-growth criteria and non-linear fracture mechanics. Journal of the Mechanics and Physics of Solids, 19, 407-418.

Broberg, K. B. (1975). On stable crack growth. Journal of the Mechanics and Physics of Solids, 23, 215-237.

Brown, H. R. (1991). A molecular interpretation of the toughness of glassy polymers. Macromolecules, 24, 2752-2756

Bucknall, C. B., \& Clayton, D. (1971). Dilatometric studies of crazing in rubbertoughened plastics. Nature (London), Physical Science, 231, 107-108.

Bucknall, C. B., Karpodinis, A., \& Zhang, X. C. (1994). A model for particle cavitation in rubber-toughened plastics. Journal of Materials Science, 29, 3377-3383.

Bucknall, C. B., \& Paul, D. R. (2009). Notched impact behavior of polymer blends: Part 1: New model for particle size dependence. Polymer, 50, 5539-5548.

Cerclé, C., Sarazin, P., \& Favis, B. D. (2013). High performance polyethylene/thermoplastic starch blends through controlled emulsification phenomena. Carbohydrate Polymers, 92, 138-148.

Chaléat, C. M., Halley, P. J., \& Truss, R. W. (2008). Properties of a plasticised starch blend. Part 1: Influence of moisture content on fracture properties. Carbohydrate Polymers, 71, 535-543.

Favis, B. D., Rodriguez-Gonzalez, F. J., \& Bruce, B. A. (2005). Method of making polymer compositions containing thermoplastic starch. In US patent 6,844,380.

Favis, B. D., Rodriguez, F., \& Ramsay, B. A. (2003). Polymer compositions containing thermoplastic starch and process of making. In US patent 6,605,657.

Fellahi, S., Favis, B. D., \& Fisa, B. (1995). Tensile dilatometry of injection-molded HDPE/PA6 blends. Journal of Materials Science, 30, 5522-5530.

Gupta, A. P., Sharma, M., \& Kumar, V. (2008). Preparation and characterization of potato starch based low density polyethylene/low density polyethylene grafted maleic anhydride biodegradable polymer composite. Polymer-Plastics Technology and Engineering, 47, 953-959.

Kaber, K. T., \& Evans, A. G. (1983). Crack deflection processes-I. Theory. Acta Metallurgica, 31, 565-576.

Kim, J. K., \& Mai, Y. W. (1991). High strength, high fracture toughness fiber composites with interface control-a review. Composites Science and Technology, 41 333-378

Kunz-Douglass, S., Beaumont, P. W. R., \& Ashby, M. F. (1980). A model for the toughness of epoxy-rubber particulate composites. Journal of Materials Science, 15, 1109-1123.

Laura, D. M., Keskkula, H., Barlow, J. W., \& Paul, D. R. (2003). Effect of rubber particle size and rubber type on the mechanical properties of glass fiber reinforced, rubber-toughened nylon 6. Polymer, 44, 3347-3361.

Laurens, C., Creton, C., \& Léger, L. (2004). Adhesion promotion mechanisms at isotactic polypropylene/polyamide 6 interfaces: role of the copolymer architecture. Macromolecules, 37, 6814-6822.

Mai, Y.-W., Wong, S.-C., \& Chen, X. (1999). Application of fracture mechanics for characterization of toughness of polymer blends. In D. R. Paul, \& C. B. Bucknall (Eds.), Polymer blends (2) (pp. 17-58). New York, NY: Wiley.

Mai, Y. W., \& Cotterell, B. (1985). Effect of specimen geometry on the essential work of plane stress ductile fracture. Engineering Fracture Mechanics, 21, 123-128.

Mai, Y. W., \& Cotterell, B. (1986). On the essential work of ductile fracture in polymers. International Journal of Fracture, 32, 105-125.

Mai, Y. W., Cotterell, B., Horlyck, R., \& Vigna, G. (1987). The essential work of plane stress ductile fracture of linear polyethylenes. Polymer Engineering and Science. 27, 804-809.

Naqui, S. I., \& Robinson, I. M. (1993). Tensile dilatometric studies of deformation in polymeric materials and their composites. Journal of Materials Science, 28, 1421-1429.

Ning, W., Jiugao, Y., Xiaofei, M., \& Ying, W. (2007). The influence of citric acid on the properties of thermoplastic starch/linear low-density polyethylene blends. Carbohydrate Polymers, 67, 446-453.

Otey, F. H., Westhoff, R. P., \& Russell, C. R. (1977). Biodegradable films from starch and ethylene-acrylic acid copolymer. Industrial and Engineering Chemistry Product research and Development, 16, 305-308. 
Pearson, R. A., \& Yee, A. F. (1991). Influence of particle size and particle size distribution on toughening mechanisms in rubber-modified epoxies. Journal of Materials Science, 26, 3828-3844.

Prachayawarakorn, J., Sangnitidej, P., \& Boonpasith, P. (2010). Properties of thermoplastic rice starch composites reinforced by cotton fiber or low-density polyethylene. Carbohydrate Polymers, 81, 425-433.

Rodriguez-Gonzalez, F. J., Ramsay, B. A., \& Favis, B. D. (2003). High performance LDPE/thermoplastic starch blends: a sustainable alternative to pure polyethylene. Polymer, 44, 1517-1526.

Sailaja, R. R. N., \& Chanda, M. (2000). Use of maleic anhydride-grafted polyethylene as compatibilizer for polyethylene-starch blends: Effects on mechanical properties. Journal of Polymer Materials, 17, 165-176.

Sailaja, R. R. N., Reddy, A. P., \& Chanda, M. (2001). Effect of epoxy functionalized compatibilizer on the mechanical properties of low-density polyethylene/plasticized tapioca starch blends. Polymer International, 50, 1352-1359.

St-Pierre, N., Favis, B. D., Ramsay, B. A., Ramsay, J. A., \& Verhoogt, H.(1997). Processing and characterization of thermoplastic starch/polyethylene blends. Polymer, 38, 647-655.

Swanson, C. L., Shogren, R. L., Fanta, G. F., \& Imam, S. H. (1993). Starch-plastic materials-preparation, physical properties, and biodegradability (a review of recent USDA research). Journal of Environmental Polymer Degradation, 1.

Taguet, A., Huneault, M. A., \& Favis, B. D. (2009). Interface/morphology relationships in polymer blends with thermoplastic starch. Polymer, 50, 5733-5743.
Tena-Salcido, C. S., Rodriguez-Gonzalez, F. J., Mendez-Hernandez, M. L., \& Contreras-Esquivel, J. C. (2008). Effect of morphology on the biodegradation of thermoplastic starch in LDPE/TPS blends. Polymer Bulletin, 60, 677-688.

(2000). Test protocol for essential work of fracture (Version 6). E.S.I.S.

Wang, S., Yu, J., \& Yu, J. (2005). Preparation and characterization of compatible thermoplastic starch/polyethylene blends. Polymer Degradation and Stability, 87, 395-401.

Wang, Y. J., Liu, W., \& Sun, Z. (2004). Effects of glycerol and PE-g-MA on morphology, thermal and tensile properties of LDPE and rice starch blends. Journal of Applied Polymer Science, 92, 344-350.

Williams, J. G. (1984). Fracture mechanics of polymers. New York, NY: Halsted Press. Wong, S.-C., Mai, Y.-W., \& Chen, X. (2003). Fracture behavior of polymer blends. In J. P. Simon (Ed.), Polymer characterization techniques and their application to blends (pp. 191-234)

Wu, J., Chan, C.-M., \& Mai, Y.-W. (1999). Study on morphology and toughening mechanisms in polymer blends by microscopic techniques. In G. O. Shonaike, \& G. P. Simon (Eds.), Polymer blends and alloys (pp. 505-548).

Wu, J., \& Mai, Y.-W. (1996). The essential fracture work concept for toughness measurement of ductile polymers. Polymer Engineering and Science, 36, 2275-2288.

Yee, A. F., \& Pearson, R. A. (1986). Toughening mechanisms in elastomer-modified epoxies. Part 1. Mechanical studies. Journal of Materials Science, 21, 2462-2474.

Yin, Q., Dong, A., Wang, J., \& Yin, Y. (2008). Rheological and thermal behavior of starch/LDPE blends containing EAA. Polymer Composites, 29, 745-749. 